the CMV-IE promoter was added $(1 \mu \mathrm{g})$ to each transfection cocktail. Forty-eight hours after transfection, cell extracts were prepared and assayed for $\beta$-galactosidase activity (26). Appropriately normalized amounts of cell extract were used for CAT assays (14). After autoradiographic exposure, the thin-layer chromotography (TLC) plates were scanned, and percent conversion values were calculated.

14. C. Gorman, L. F. Moffat, B. Howard, Mol. Cell. Biol. 2, 1044 (1982).

15. Each transfection experiment was performed in duplicate at least four times. The percent conversion values shown represent the average of duplicates in a representative experiment. The variation among experiments was $<10 \%$. The transfection efficiency (as measured by $\beta$-galactosidase activity in cell extracts) varied $<10 \%$ among all plates in a particular experiment. We have detected no toxic or growth inhibitory effects (as measured by reductions in $\beta$-galactosidase activity or cell number) as a result of expressing WT1 or EGR-1 in transient assays.

16. D. M. Cook and F. J. Rauscher III, unpublished data.

17. A. J. Buckler et al., Mol. Cell. Biol. 11, 1707 (1991).

18. The insertion of 3- and 17-amino acid segments into the WTl coding sequence and the construction of chimeric wt1-egr-1 genes was accomplished with sequential PCR-mediated mutagenesis (27). The amino acid sequence of the 17-amino acid insertion was taken from the LK15 clone of WT1 [M. Gessle et al., Nature 343, 744 (1990)]. After each round of PCR, the complete coding region of the gene was sequenced to guard against Taq polymerase-induced errors. Two of the deletion mutants of WT1 were created with unique Bam HI (WT1,179-429) and Xmn I (WT1,1-364) restriction sites in the WT33 coding sequence (1). The WT1,294-429 deletion corresponded to the previously described WTZF protein (6) and included the six histidine residues at the $\mathrm{NH}_{2}$-terminus. The internally deleted protein WTl(179-294) was created by first cleaving the WTI and WTZF (6) genes at unique Bam HI sites. The restriction sites were blunted by filling in with the large fragment of DNA polymerase, and the gene fragments were fused in a blunt-end ligation reaction. The fusion of WTI and WTZF in this manner regenerated the proper frame of translation and resulted in the introduction of one additional arginine residue at the site of fusion. Each gene was cloned into pGEM7Zf + vector and used to generate synthetic RNA by in vitro transcription. The RNAs were used to program rabbit reticulocyte lysates. The DNA binding activity of each protein was assessed by gel retardation assays with a ${ }^{32} \mathrm{P}$-labeled oligonucleotide probe that contained an EGR binding site $(6,28)$.

19. The full-length WTI and EGR-I proteins displayed identical apparent affinity for the EGR binding site when measured in vitro by gel retardation assays. No detectable association was observed between EGR-1 and WT1 in coimmunoprecipitation assays (21).

20. For generating chimeric proteins we defined the zinc finger region of WTl as extending from amino acid 307 to the natural stop codon at position 429 . This stop codon occurs 11 amino acids after the last zinc finger in WT1. To ensure that this same number of amino acids was present after the last zinc finger in EGR-1, a stop codon was introduced at amino acid position 427 in the EGR-1 coding sequence (the natural stop codon in egr-1 occurs 117 amino acids $\mathrm{COOH}$-terminal to the last zinc finger). Thus, the EGR-1 zinc finger region we used for preparing chimeric proteins spanned amino acids 337 to 427 . The zinc finger regions of these two proteins displayed identical affinities and DNA binding specificities for the EGR sequence (Fig. 2B).

21. S. L. Madden and F. J. Rauscher III, unpublished data.

22. J. I. Morgan and T. Curran, Trends Neurosci. 12, 459 (1989)

23. N. Mermod, E. A. O’Neill, T. J. Kelly, R. Tjian, Cell 58, 741 (1989); A. J. Courey and R. Tjian, ibid. 55 , 887 (1988)

24. S. Fields and S. K. Jang, Science 249, 1046 (1990); L. Raycroft, H. Wu, G. Lozano, ibid., p. 1049.

25. S. Andersson et al., J. Biol. Chem. 264, 8222 (1989).
26. R. R. Spaete and E. S. Mocarski, J. Virol. 56, 136 (1985).

27. S. N. Ho et al., Gene 77, 51 (1989).

28. F. J. Rauscher III, P. J. Voulalas, B. R. Franza, Jr., T. Curran, Genes Dev. 2, 1687 (1988).

29. We thank T. Curran and G. Rovera for encouragement and many helpful discussions; P. Reddy and S. Shore for NIH 3T3 cells; R. Ricciardi for 293 cells; D. Housman for the WT33 cDNA clone; and B. Knowles, R. Weinmann, and G. Rovera for critically reviewing the manuscript. Supported by grants from the USPHS [CA-23413, CA-52009 (F.J.R.), CA-0917-15 (J.F.M.)], core grant (CA10817), the W. W. Smith Charitable Trust (F.J.R.), and the Hansen Memorial Trust (F.J.R.) V.P.S. is supported by the Howard Hughes Medical Institute. F.J.R. is a Pew Scholar in the Biomedical Sciences.

14 May 1991; accepted 16 August 1991

\title{
The Roles of the Subunits in the Function of the Calcium Channel
}

\author{
Dafna Singer, Martin Biel, Ilana Lotan, Veit Flockerzi, \\ Franz HOFMANN, NATHAN DASCAL*
}

Dihydropyridine-sensitive voltage-dependent L-type calcium channels are critical to excitation-secretion and excitation-contraction coupling. The channel molecule is a complex of the main, pore-forming subunit $\alpha_{1}$ and four additional subunits: $\alpha_{2}, \delta, \beta$, and $\gamma\left(\alpha_{2}\right.$ and $\delta$ are encoded by a single messenger RNA). The $\alpha_{1}$ subunit messenger RNA alone directs expression of functional calcium channels in Xenopus oocytes, and coexpression of the $\alpha_{2} / \delta$ and $\beta$ subunits enhances the amplitude of the current. The $\alpha_{2}$, $\delta$, and $\gamma$ subunits also have pronounced effects on its macroscopic characteristics, such as kinetics, voltage dependence of activation and inactivation, and enhancement by a dihydropyridine agonist. In some cases, specific modulatory functions can be assigned to individual subunits, whereas in other cases the different subunits appear to act in concert to modulate the properties of the channel.

$\mathrm{T}$

HE DIHYDROPYRIDINE (DHP)-SENsitive $\mathrm{Ca}^{2+}$ channel protein of the skeletal muscle (SM) consists of five subunits, $\alpha_{1}, \alpha_{2}, \delta, \beta$, and $\gamma(1)$. The $\alpha_{1}$ subunit contains the binding site for DHPs and other classical organic $\mathrm{Ca}^{2+}$ channel blockers (2), is the pore-forming subunit $(1-4)$, and is indispensable for the function of the channel (5-8). A single $\alpha_{2} / \delta$ mRNA encodes the precursor protein $\alpha_{2} / \delta$, which is proteolysed into the $\delta$ and $\alpha_{2}$ subunits, linked by disulfide bonds $(1,9)$. The $\mathrm{cDNAs}$ of the $\alpha_{2} / \delta, \beta$, and $\gamma$ subunits have been cloned from SM (10-13). Identical or homologous proteins are found in brain $\left(\alpha_{2} / \delta\right.$, $\beta)$, smooth muscle $\left(\alpha_{2} / \delta, \gamma\right)$, and heart $\left(\alpha_{2} / \delta, \beta\right)(6,10-15)$. Functional $\mathrm{Ca}^{2+}$ channels can be expressed in Xenopus oocytes injected with RNA of the $\alpha_{1}$ subunits from heart, smooth muscle, and brain (6-8); coexpression of $S M \alpha_{2} / \delta$ and $\beta$ with cardiac and brain $\alpha_{1}$ subunit enhances the expressed $\mathrm{Ca}^{2+}$ currents, whereas the $\gamma$ subunit is without effect $(6,8)$. The electrophysiolog-

D. Singer, I. Lotan, N. Dascal, Department of Physiology and Pharmacology, Sackler School of Medicine, Tel Aviv University, Ramat Aviv 69978, Israel.

M. Biel and F. Hofmann, Institut für Pharmakologie und Toxikologie der Technischen Universitat Munchen, Biedersteiner St. 29, 8000 Munchen 40, Germany. V. Flockerzi, Institut für Medizinische Biochemie, Universitat des Saarlandes, D-6650 Homburg-Saar, Germany.

*To whom correspondence should be sent at P.O. Box 39048, Tel Aviv 69978, Israel. ical properties of the channel have been reported to be unaffected by the auxiliary subunits $(6,8)$. We have investigated this problem by coexpressing the $\mathrm{Ca}^{2+}$ channel subunits in various combinations in Xenopus oocytes and examining the macroscopic characteristics of the current through the emerging $\mathrm{Ca}^{2+}$ channels.

cRNAs of cardiac $\alpha_{1}$ subunit and of SM $\alpha_{2} / \delta, \beta$, and $\gamma$ subunits were synthesized in vitro and injected into Xenopus oocytes (16). After cRNA injection (4 to 5 days), we measured currents using the two-electrode voltage-clamp method, usually in a solution containing $40 \mathrm{mM} \mathrm{BaCl}$ (16), because $\mathrm{Ba}^{2+}$ results in a larger current through the $\mathrm{Ca}^{2+}$ channel.

Uninjected oocytes displayed a small endogenous $\mathrm{Ba}^{2+}$ current, $I_{\mathrm{Ba}}$ (Table 1 ), that was insensitive to the DHP agonist (-) Bay K 8644 (Bay K) (17). A small, Bay K-sensitive $I_{\mathrm{Ba}}$ was observed in oocytes injected with the cRNA of the $\alpha_{1}$ subunit alone ( 0 to $-50 \mathrm{nA}$ ) (Fig. 1). Coexpression in the $\alpha_{2} / \delta$ or $\beta$ subunit with $\alpha_{1}$ consistently enhanced the expressed currents, and coexpression of both $\alpha_{2} / \delta$ and $\beta$ with $\alpha_{1}$ caused more than additive increase in the amplitude of $I_{\mathrm{Ba}}$ (Table 1). The $\gamma$ subunit did not have a consistent effect on the amplitude of $I_{\mathrm{Ba}}$ (Table 1). Since the auxiliary subunits similarly enhance the expression of a brain $\mathrm{Ca}^{2+}$ channel (6), this phenomenon may be common to a variety of $\mathrm{Ca}^{2+}$ channels. 


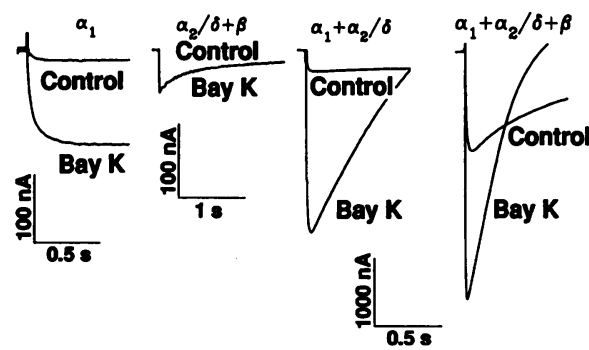

Injection of cRNA combinations that did not contain the cardiac $\alpha_{1}$ cRNA (Table 1 and Fig. 1), yielded small, Bay $\mathrm{K}$-insensitive currents that were larger than, but otherwise similar to, the $I_{\mathrm{Ba}}$ of the native oocyte and were similarly $(17,18)$ blocked by $\mathrm{Ni}^{2+}$ (not shown). These currents probably resulted from the association of the newly synthesized $\alpha_{2} / \delta$ and $\beta$ subunits with a native DHP-insensitive $\alpha_{1}$ subunit existing in the oocyte. The $\gamma$ subunit was apparently unable to associate with endogenous $\alpha_{1}$, and even caused a decrease in the current amplitude (compare groups $\alpha_{2} / \delta+$ $\beta$ and $\alpha_{1}+\beta+\gamma$ ) (Table 1), possibly because of the competition of RNAs for polysomes (19).

The $I_{\mathrm{Ba}}$ (at $0 \mathrm{mV}$ ) was potentiated by Bay $\mathrm{K}(0.5 \mu \mathrm{M})$ in all groups containing the $\alpha_{1}$ subunit (Fig. 1), but with different efficiency; $\alpha_{1}+\alpha_{2} / \delta+\beta$ was the least sensitive combination (Table 1). This effect could result from a direct influence of the auxiliary subunits on drug binding or from different voltage dependence of $I_{\mathrm{Ba}}$ in the different groups (see below). A DHP blocker, $(+)$ PN 200-110 (1 $\mu M)$, and a phenylalkylamine blocker, verapamil $(20 \mu \mathrm{M})$, effectively blocked $I_{\mathrm{Ba}}$ in grcups containing the cardiac $\alpha_{1}$.

To investigate the macroscopic activation of $I_{\mathrm{Ba}}$, we measured the time by which $I_{\mathrm{Ba}}$ reaches $90 \%$ of its peak amplitude $(90 \%$ $t t p)$. The $90 \% \mathrm{ttp}$ at $0 \mathrm{mV}$ was independent of $I_{\mathrm{Ba}}$ amplitude within each group and was uniform in all groups containing $\alpha_{2} / \delta(\sim 20$ $\mathrm{ms}$ ), but was slower in groups without $\alpha_{2} / \delta$ (34 to $56 \mathrm{msec}$ ) (Fig. 2A and Table 1). Combinations that presumably associated with the native $\alpha_{1}\left(\alpha_{2} / \delta+\beta\right.$ and $\alpha_{2} / \delta+$ $\beta+\gamma)$ had the fastest activation $(\sim 10 \mathrm{msec})$ (Table 1). Activation of $I_{\mathrm{Ba}}$ directed by the cardiac $\alpha_{1}$ subunit alone is a few tens of milliseconds, which is slower than in cardiac cells but several times faster than in skeletal muscle $(>150 \mathrm{msec})(20)$. Thus, the activation kinetics of $\mathrm{Ca}^{2+}$ channels is determined both by nature of the $\alpha_{1}$ subunit and by subunit composition, especially by $\alpha_{2} / \delta$.

We also investigated the kinetics of macroscopic inactivation of $I_{\mathrm{Ba}}$. The decay rate was quantified as the decrease in $I_{\mathrm{Ba}}$ from the peak to the value $770 \mathrm{msec}$ after the
Fig. 1. Examples of $I_{\mathrm{Ba}}$ obtained by steps from -100 to $0 \mathrm{mV}$ in oocytes injected with $\mathrm{cRNAs}$ of various subunits, and the effect of $0.5 \mu \mathrm{M}(-)$ Bay K 8644. Net $I_{\mathrm{B} 2}$ was obtained by the $\mathrm{Cd}^{2+}$. subtraction procedure (by subtraction of currents recorded in the presence of 0.2 to $0.4 \mathrm{mM} \mathrm{Cd}^{2+}$ ) in $40 \mathrm{mM} \mathrm{BaCl}$ in all figures.

beginning of depolarization, expressed as percent of peak amplitude (dec 770 ) (21). The decay of $I_{\mathrm{Ba}}$ became faster when the current exceeded 1.5 to $2 \mu \mathrm{A}$, suggesting the interference of a current-dependent inactivation process (22) or a $\mathrm{Ba}^{2+}$-activated outward current, probably carried by $\mathrm{Cl}^{-}$, since it was not observed when methanesulfonate replaced $\mathrm{Cl}^{-}$in the external solution (23). However, in all groups, for $I_{\mathrm{Ba}}<850 \mathrm{nA}$, the decay of $I_{\mathrm{Ba}}$ did not depend on the entry of $\mathrm{Ba}^{2+}$, because (i) $\operatorname{dec}_{770}$ was independent of current amplitude, and (ii) the inactivation kinetics were not appreciably altered by replacing external $\mathrm{Cl}^{-}$with methanesulfonate (not shown). Therefore, we only analyzed inactivation kinetics of currents $<850$ nA.

The inactivation kinetics depended on subunit composition (Fig. 2B). At $0 \mathrm{mV}$, the current directed by the $\alpha_{1}$ subunit alone showed little time-dependent inactivation; addition of either $\beta$ or $\alpha_{2} / \delta$ to $\alpha_{1}$ did not significantly accelerate the decay. However, the decay was much faster in groups containing the $\gamma$ subunit or both $\alpha_{2} / \delta$ and $\beta$ (Fig. 2B and Table 1). In most groups, the decay of $I_{\mathrm{Ba}}$ became faster with stronger
Fig. 2. Activation and inactivation kinetics of $I_{\mathrm{Ba}}$ at 0 $\mathrm{mV}$. (A) Comparison of the rising phase of $I_{\mathrm{Ba}}$ in two oocytes from groups $\alpha_{1}+\gamma$ and $\alpha_{1}+\alpha_{2} / \delta+\gamma$. (B) Decay of $I_{\mathrm{Ba}}$ of comparable amplitudes in oocytes of different groups. Relatively small currents are shown to allow composition with the $\alpha_{2} / \delta+\beta$ combination without scaling. In all groups, the kinetics of the decay was unchanged in the range 60 to $800 \mathrm{nA}$. The "addition" of $\gamma$ produced the strongest acceleration (compare $\alpha_{1}$ and $\alpha_{1}+\gamma, P<0.01 ; \alpha_{1}+\alpha_{2} / \beta$ and $\alpha_{1}+\alpha_{2} / \delta+\gamma, P<0.01$; $\alpha_{1}+\beta$ and $\alpha_{1}+\beta+\gamma, P<0.02 ; \alpha_{1}+\alpha_{2} / \delta+\beta$ and $\left.\alpha_{1}+\alpha_{2} / \delta+\beta+\gamma, P<0.05\right)$. The addition of $\alpha_{2} / \delta$ or $\beta$ accelerated the decay in one case each $\left(\alpha_{1}+\alpha_{2} / \delta\right.$ or $\alpha_{1}+\beta$ versus $\alpha_{1}+\alpha_{2} / \delta+\beta, P<$ $0.001)$ but not in other cases $\left(\alpha_{1}\right.$ versus $\alpha_{1}+\beta, P>0.2 ; \alpha_{1}$ versus $\alpha_{1}+\alpha_{2} / \delta, P>0.05 ; \alpha_{1}+\gamma$ versus $\alpha_{1}+\beta+\gamma, P>0.5 ; \alpha_{1}+\alpha_{2} / \delta+\gamma$ versus $\alpha_{1}+\alpha_{2} / \delta+\beta+\gamma, P>0.1 ; \alpha_{1}+\gamma$ versus $\alpha_{1}+\alpha_{2} / \delta$ $+\gamma, P>0.5)$. $P$ was calculated with a two-tailed $t$ test with a Bonferroni-like correction.
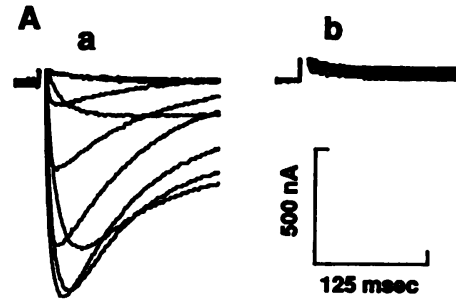

Fig. 3. Voltage-dependence of $I_{\mathrm{Ba}}$ activation. (A) An example of the $\mathrm{Cd}^{2+}$-subtraction procedure used to obtain net $I_{\mathrm{Ba}}:$ a, total currents evoked by depolarizing pulses to different voltages; $\mathrm{b}$, the same as $\mathrm{a}$ in the presence of $0.4 \mathrm{mM} \mathrm{CdCl}$; c, net $I_{\mathrm{Ba}}$ after digital subtraction of traces in $b$ from those in a, with voltages (in millivolts) shown near each trace; $d$, the $I-V$ curve in the same cell as a through $c$. (B) $I-V$ curves in representative oocytes of four other groups. The currents were normalized to the peak.

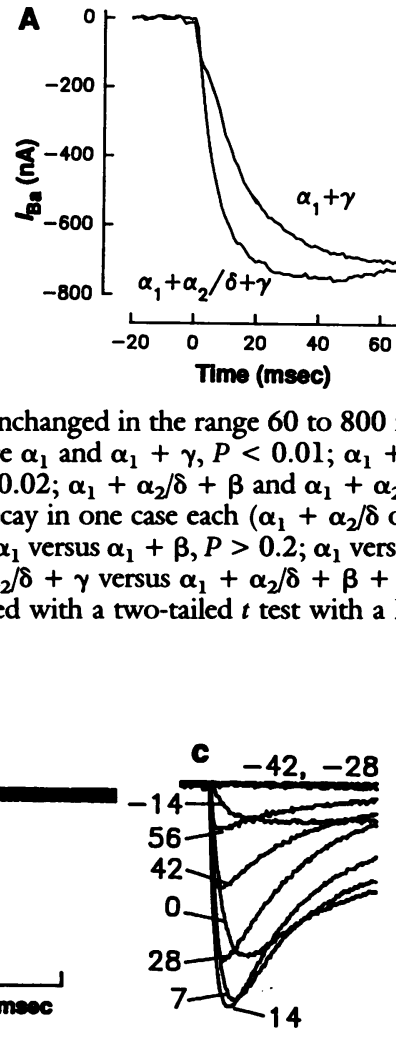

B

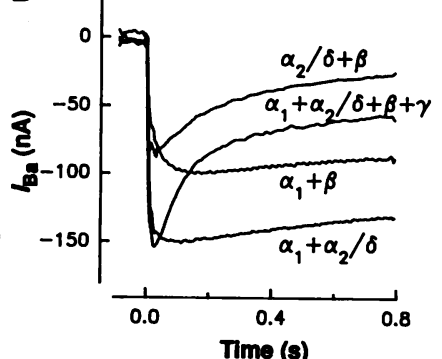

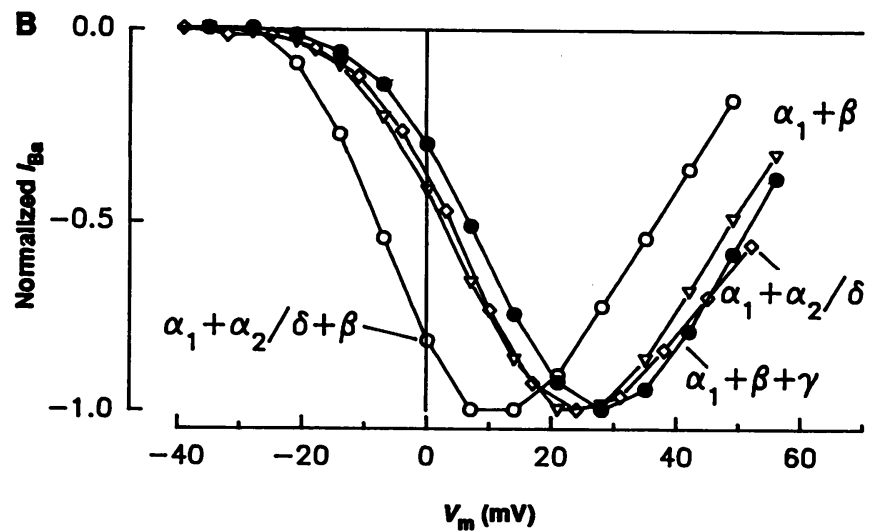

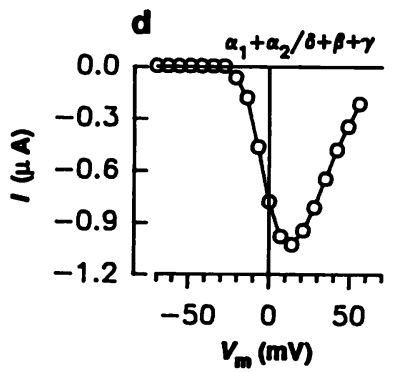


depolarization, and this phenomenon did not depend on current amplitude (Fig. 3A, $\mathrm{C})$, suggesting a voltage-dependent inactivation process (22).

The voltage dependence of the channel activation was determined mainly by $\alpha_{1}$, since the current-voltage $(I-V)$ curves of currents through channels directed by the $\alpha_{1}$ subunit alone $(6,7)$ are similar to those directed by most other subunit combinations (Fig. 3). The peak of the $I-V$ curve in most groups was between 15 and $30 \mathrm{mV}$. However, in the $\alpha_{1}+\alpha_{2} / \delta+\beta$ group $I_{\mathrm{Ba}}$ activated and peaked at more negative potentials (Fig. 3 and Table 1), again implying a modulation by, and a synergy between the $\alpha_{2} / \delta$ and $\beta$ subunits. Addition of $\gamma$ to most subunit combinations slightly shifted the peak of the $I-V$ curve to more positive voltages (Table 1 ).
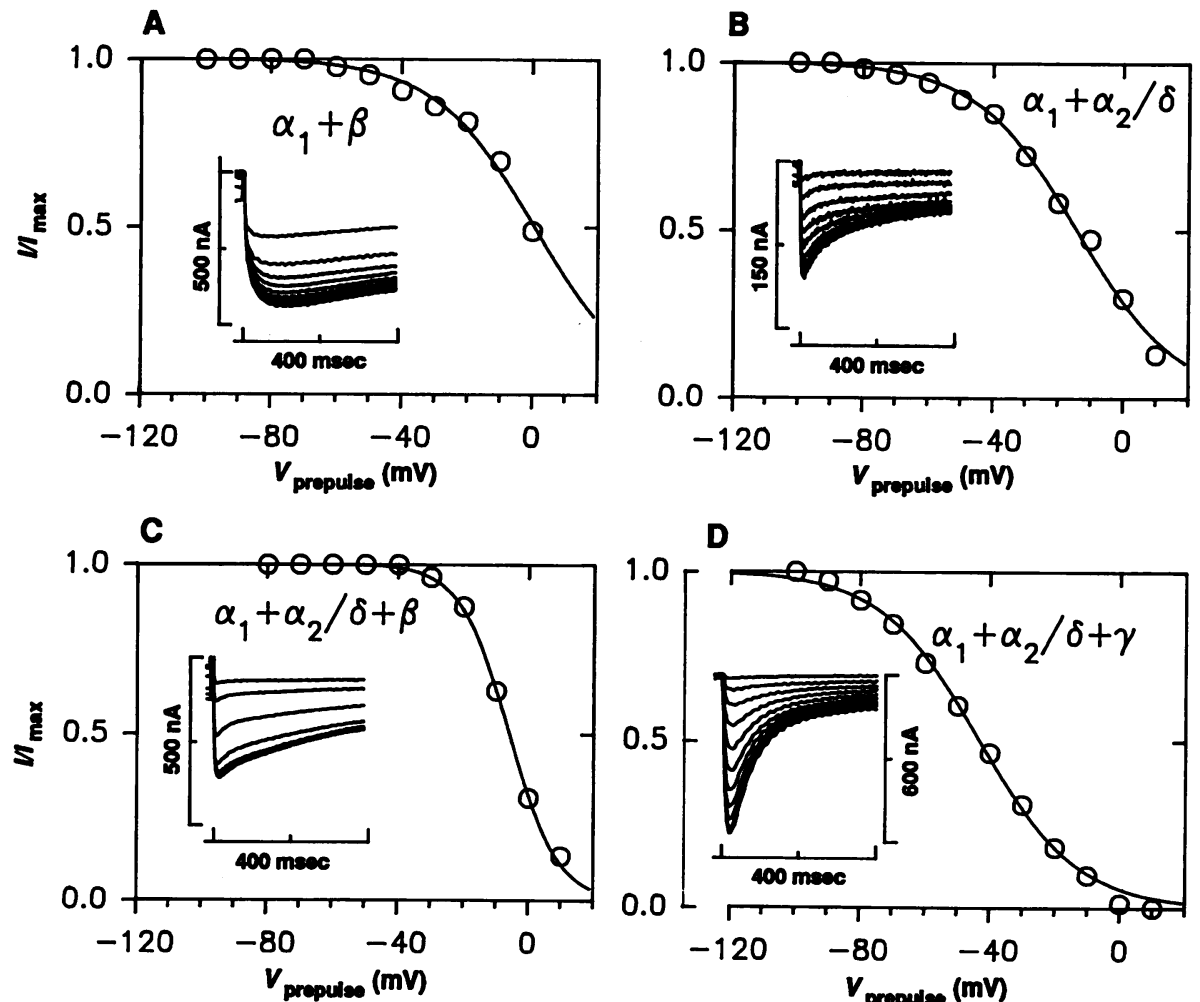

Fig. 4. Voltage dependence of inactivation of $I_{\mathrm{Ba}}$. (A through D) Examples of inactivation curves and net $I_{\mathrm{Ba}}$ (insets) in representative oocytes from various groups. The currents were examined with a two-pulse protocol: a 5 -s prepulse to different voltages (starting from $-100 \mathrm{mV}$, with a $10-\mathrm{mV}$ increment), followed by a test pulse to $20 \mathrm{mV}$. The curves were drawn with the Bolzmann equation (24) with the following parameters in (A through D), respectively: $V_{1 / 2}, 0.8,-14.4$, $-5.8,-43 \mathrm{mV} ; K_{\mathrm{i}}, 15.5,15.6,7.6$, $15.3 \mathrm{mV}$. (E) Average inactivation curves drawn with the Bolzmann equa-

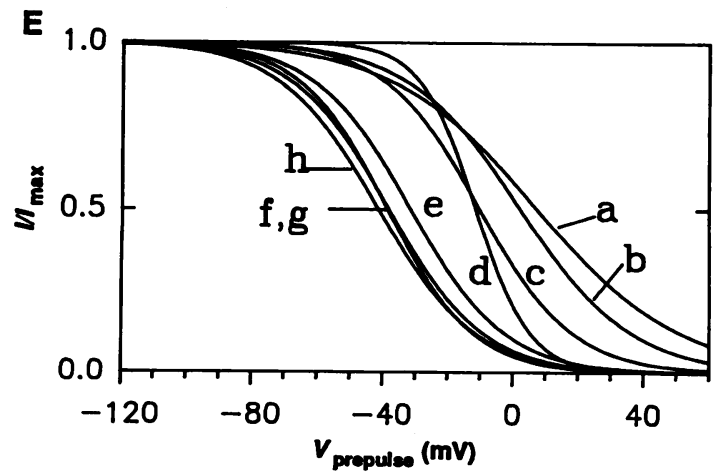

tion and the parameters from Table 2. The letters near the traces correspond to the subunit combinations: a, $\alpha_{1}$ in the presence of Bay K (25); b, $\alpha_{1}+\beta ; c, \alpha_{1}+\alpha_{2} / \delta ; d, \alpha_{1}+\alpha_{2} / \delta+\beta ;$ e, $\alpha_{1}$ $+\beta+\gamma ; f, \alpha_{1}+\alpha_{2} / \delta+\beta+\gamma ; g, \alpha_{2} / \delta+\beta ; h, \alpha_{1}+\alpha_{2} / \delta+\gamma$. cardiac $\alpha_{1}$, suggesting the $\gamma$ does not associate with the endogenous $\alpha_{1}$ or does not affect its properties.

In $2 \mathrm{mM} \mathrm{Ba}{ }^{2+}, V_{1 / 2}$ was shifted to more negative voltages compared to $40 \mathrm{mM} \mathrm{Ba}^{2+}$ (Table 2), and this change was larger in the presence of the $\gamma$ subunit than in its absence (Table 2), suggesting that the $\gamma$ subunit causes addition of negative charges in the vicinity of the external mouth of the channel (26). Thus, some of its external, negatively charged groups may be close to the voltagesensing parts of $\alpha_{1}$, and this implies an intimate contact and a strong interaction between $\gamma$ and $\alpha_{1}$ subunits.

In this report we demonstrate that the auxiliary subunits of the $\mathrm{SM} \mathrm{Ca}^{2+}$ channel have pronounced effects on the biophysical and pharmacological properties of the cardiac $\mathrm{Ca}^{2+}$ channel: kinetics of activation and inactivation, voltage dependence, and enhancement by Bay K. Our data suggest direct interactions between $\alpha_{2} / \delta$ or $\gamma$ subunits with $\alpha_{1}$, because each of them alters the properties of the channel when coexpressed with $\alpha_{1}$ in the absence of the other auxiliary subunits (although interference of endogenous $\alpha_{2} / \delta, \beta$, or $\gamma$ cannot be completely excluded). The effect of the $\beta$ subunit alone on the biophysical parameters of the channel is usually negligible, and its direct contact with $\alpha_{1}$ is less certain. The combination of $\alpha_{2} / \delta$ and $\beta$ subunits is synergistic for both expression of the channel and channel properties, conferring activation at more negative voltages, steep voltage dependence of inactivation, and less enhancement by Bay $\mathrm{K}$ (at $0 \mathrm{mV}$ ). This suggests a strong interaction between $\alpha_{2} / \delta$ and $\beta$ (directly or via $\alpha_{1}$ ).

Our data and that of others (27) show that the $\alpha_{1}$ subunit is central in determining the kinetics and the voltage dependence of activation. This is supported by theoretical considerations (4). However, other subunits have modulatory effects: $\alpha_{2} / \delta$ (independent of the presence of $\beta$ or $\gamma$ ) fine tunes the activation kinetics of the cardiac channel expressed in the oocyte; $\alpha_{2} / \delta$ combined with $\beta$ increase the voltage sensitivity of activation.

The auxiliary subunits are crucial in determining both the kinetics and voltage-dependence of the inactivation process; this result is in contrast to the fact that the inactivation properties of the voltage-dependent $\mathrm{Na}^{+}$ and $\mathrm{K}^{+}$channels are determined mainly by their pore-forming subunits (28). Addition of $\alpha_{2} / \delta, \alpha_{2} / \delta+\beta$, or $\gamma$ to $\alpha_{1}$ sharply increases the voltage sensitivity of the inactivation process; $\alpha_{2} / \delta+\beta$ and $\gamma$ but not $\beta$ also strongly accelerate the current decay. The effect of the $\gamma$ subunit is especially significant. Once present, $\gamma$ dominates the inactivation process, making it faster and more sensitive to voltage. This appears to be a voltage- rather than a 
Table 1. The characteristics of $I_{\mathrm{Ba}}$ directed by different subunit cRNA combinations. The current amplitudes were measured at $0 \mathrm{mV}$ in a solution containing $40 \mathrm{mM} \mathrm{BaCl} 2$. The entries are mean $\pm S E M$; numbers of oocytes and frogs $(n, N)$ are indicated in the parentheses. $\mathrm{Cd}^{2+}$. subtraction procedure was used in most cases to obtain net $I_{\mathrm{Ba}}$; in some cases, only leak subtraction was performed (5). Column 2 summarizes experiments in which 3.3 to $5 \mathrm{ng}$ cRNA (of each subunit) was injected into the oocyte. Column 3 relates only to cells with $I_{\mathrm{Ba}}$ over $-10 \mathrm{nA}$ in which the effect of $(-)$ Bay $\mathrm{K} 8644$ was tested. The increase in $I_{\mathrm{Ba}}$ caused by Bay $\mathrm{K}$ was calculated in each cell as [(amplitude in Bay $\mathrm{K}, \%$ of control) $100 \%$ ], where "control" denotes $I_{\mathrm{Ba}}$ before application of Bay $\mathrm{K}$. In columns 4 to 6 , the oocytes were injected with between 0.6 and $25 \mathrm{ng}$ of cRNA (of each subunit) per oocyte; only cells in which net $I_{\mathrm{Ba}}$ was obtained by the $\mathrm{Cd}^{2+}$-subtraction procedure are summarized. In column 5 , only cells in which $I_{\mathrm{Ba}}$ did not exceed $-850 \mathrm{nA}$ were taken into account. NT, not tested.

\begin{tabular}{|c|c|c|c|c|c|}
\hline 1 & 2 & 3 & 4 & 5 & 6 \\
\hline $\begin{array}{c}\text { Subunit } \\
\text { combination }\end{array}$ & Amplitude (nA) & $\begin{array}{c}\text { Increase in } I_{\mathrm{Ba}} \text { by } \\
\text { Bay } \mathrm{K}(\%)\end{array}$ & $\begin{array}{c}90 \% \text { ttp } \\
\text { (msec) }\end{array}$ & $\operatorname{dec}_{770}(\%)$ & Peak $I-V(\mathrm{mV})$ \\
\hline$\alpha_{1}$ alone & $-5 \pm 1(21,4)$ & $583 \pm 126(5,3)$ & $56 \pm 9(8,2)$ & $4 \pm 3(5,1)$ & $\mathrm{NT}^{*}$ \\
\hline$\alpha_{1}+\alpha_{2} / \delta$ & $-179 \pm 22(49,10)$ & $720 \pm 85(27,9)$ & $20 \pm 1(26,5)$ & $20 \pm 3(19,4)$ & $21 \pm 1(11,5)$ \\
\hline$\alpha_{1}+\beta$ & $-92 \pm 17(19,4)$ & $339 \pm 113(17,5)$ & $44 \pm 3(17,4)$ & $11 \pm 3(8,2)$ & $24 \pm 2(8,2)$ \\
\hline$\alpha_{1}+\gamma$ & $-123 \pm 57(23,4) \dagger$ & $348 \pm 62(6,3)$ & $34 \pm 3(6,2)^{\prime}$ & $44 \pm 3(4,1)$ & $33,35(2,1)$ \\
\hline$\alpha_{1}+\alpha_{2} / \delta+\beta$ & $-1625 \pm 190(48,8)$ & $169 \pm 34(14,4)$ & $19 \pm 1(61,7)$ & $43 \pm 3(21,5)$ & $9 \pm 2(13,3)$ \\
\hline$\alpha_{1}+\alpha_{2} / \delta+\gamma$ & $-912 \pm 254(26,5) \dagger$ & $402 \pm 122(6,2)$ & $20 \pm 1(19,5)$ & $45 \pm 4(6,3)$ & $23 \pm 6(4,3)$ \\
\hline$\alpha_{1}+\beta+\gamma$ & $-87 \pm 13(14,3) \dagger$ & $587 \pm 127(9,2)$ & $39 \pm 3(11,3)$ & $39 \pm 7(10,3)$ & $28 \pm 2(5,1)$ \\
\hline $\begin{array}{c}\alpha_{1}+\alpha_{2} / \delta+ \\
\beta+\gamma\end{array}$ & $-1076 \pm 362(19,5) \dagger$ & $425 \pm 154(3,1)$ & $20 \pm 1(18,5)$ & $54 \pm 4(10,4)$ & $19 \pm 1(11,4)$ \\
\hline$\alpha_{2} / \delta+\beta$ & $-46 \pm 7(32,4)$ & $19 \pm 14(17,3)$ & $10 \pm 1(18,3)$ & $63 \pm 5(6,1)$ & $15 \pm 1(7,2)$ \\
\hline$\alpha_{2} / \delta+\beta+\gamma$ & $-20 \pm 4(26,4)$ & $3 \pm 4(9,2)$ & $10 \pm 1(8,2)$ & NT & NT \\
\hline$\alpha_{2} / \delta+\gamma$ & $-10 \pm 3(8,1)$ & NT & NT & NT & NT \\
\hline Uninjected & $-4 \pm 2(29,8)$ & NT & NT & NT & $\mathrm{NT}^{*}$ \\
\hline
\end{tabular}

"Peak $I-V$ in oocytes injected with cardiac $\alpha_{1}$ cRNA alone is about $25 \mathrm{mV}(6)$, and of $I_{\mathrm{B}_{2}}$ in native oocytes is about $15 \mathrm{mV}(17)$. †Mean $I_{\mathrm{Ba}}$ in pairs of groups differing by the presence of $\gamma$ were compared. $I_{\mathrm{Ba}}$ in the $\alpha_{1}+\alpha_{2} / \delta+\gamma$ group showed strong frog-to-frog variability and was normalized with respect to $I_{\mathrm{Ba}}$ in the $\alpha_{1}+\alpha_{2} / \delta$ group in oocytes of the same frogs; this procedure gave ratios between 1 and 5.7 in different experiments (mean $2.0 \pm 0.7$,

Table 2. Parameters of the voltage dependence of steady-state inactivation of $I_{\mathrm{Ba}}$ directed by different subunit cRNA combinations. The entries in columns $2,3,5$, and 6 are mean $\pm S E M$, except when only one or two cells have been examined, in which cases the values from each cell are presented. The entries in columns 4 and 7 are the number of oocytes $(n)$ and frogs $(N)$.

\begin{tabular}{|c|c|c|c|c|c|c|}
\hline 1 & 2 & 3 & 4 & 5 & 6 & 7 \\
\hline \multirow{2}{*}{ Group } & \multicolumn{3}{|c|}{ In $40 \mathrm{mM} \mathrm{Ba}^{2+}$} & \multicolumn{3}{|c|}{ In $2 \mathrm{mM} \mathrm{Ba}^{2+}$} \\
\hline & $V_{1 / 2}(\mathrm{mV})$ & $K_{\mathrm{i}}(\mathrm{mV})$ & $n, N$ & $V_{1 / 2}(\mathrm{mV})$ & $K_{\mathrm{i}}(\mathrm{mV})$ & $n, N$ \\
\hline$\alpha_{1}$ alone $\dagger$ & $10.4 \pm 2.2$ & $24.3 \pm 2.8$ & 6,4 & & & \\
\hline$\alpha_{1}$ alone & 11.1 & 17.9 & 1 & & & \\
\hline$\alpha_{1}+\alpha_{2} / \delta$ & $-10.2 \pm 1.1$ & $14.5 \pm 0.7$ & 6,3 & & & \\
\hline$\alpha_{1}+\beta$ & $2.4 \pm 3.6$ & $17.3 \pm 2.8$ & 7,3 & & & \\
\hline$\alpha_{1}+\gamma$ & $-45 ;-45.3$ & $18.5 ; 20.6$ & 2,1 & & & \\
\hline$\alpha_{1}+\gamma \dagger$ & $-52 ;-49.8$ & $20 ; 19.1$ & 2,1 & & & \\
\hline$\alpha_{1}+\alpha_{2} / \delta+\beta^{*}$ & $-11.4 \pm 1.2$ & $8.5 \pm 0.7$ & 8,4 & $-25.0 \pm 0.9$ & $11.3 \pm 0.4$ & 6,3 \\
\hline$\alpha_{1}+\alpha_{2} / \delta+\gamma$ & $-41.3 \pm 1.9$ & $15.1 \pm 0.6$ & 12,4 & $-65.4 ;-68.9$ & $11.1 ; 7.6$ & 2,1 \\
\hline$\alpha_{1}+\beta+\gamma^{*}$ & $-31.4 \pm 1.2$ & $14.7 \pm 0.6$ & 5,1 & & & \\
\hline$\alpha_{1}+\alpha_{2} / \delta+$ & $-38.5 \pm 2.3$ & $13.4 \pm 0.8$ & 5,4 & $-61.8 ;-62$ & $11.8 ; 11.7$ & 2,2 \\
\hline $\begin{array}{l}\alpha_{2} / \delta+\beta \\
\alpha_{2} / \delta+\beta+\gamma\end{array}$ & $\begin{array}{l}-37.3 \pm 4.2 \\
-32.2 ;-44\end{array}$ & $\begin{array}{l}14.7 \pm 1.0 \\
17.2 ; 13.9\end{array}$ & $\begin{array}{l}6,2 \\
2,1\end{array}$ & & & \\
\hline
\end{tabular}

*The results obtained in solutions with $40 \mathrm{mM} \mathrm{BaCl}_{2}$ and $40 \mathrm{mM}$ barium methanesulfonate were pooled, since no significant differences in inactivation parameters were detected in these two solutions. In other groups, all results were obtained in $40 \mathrm{mM} \mathrm{BaCl}_{2}$ solution (16). In the presence of $0.5 \mu \mathrm{M}$ Bay $\mathrm{K}$.

current-dependent phenomenon, since in the presence of $\gamma I_{\mathrm{Ba}}$ is inactivated at voltages that do not cause any current flow through the channel (Figs. 3 and 4).

Some of the modulatory effects of the auxiliary subunits may be due to inappropriate interactions between $S M$ and cardiac channel subunits. Nevertheless, the channel formed by $\alpha_{1}+\alpha_{2} / \delta+\beta$ most closely resembles the cardiac $\mathrm{Ca}^{2+} \mathrm{L}$ channels: slow but obvious inactivation with $\mathrm{Ba}^{2+}$ as the charge carrier, little inactivation at membrane voltages more negative than $-40 \mathrm{mV}$, fast activation, $K_{\mathrm{i}}$ of 8 to $9 \mathrm{mV}(29)$. The channel composed of all four subunits $\left(\alpha_{1}+\right.$ $\left.\alpha_{2} / \delta+\beta+\gamma\right)$ differs from $\alpha_{1}+\alpha_{2} / \delta+\beta$ mostly in voltage dependence of inactivation, resembling the $\mathrm{L}$ channels in mammalian SM myocytes and in smooth muscle cells (30). This is consistent with the presence of RNA homologous to that of the SM $\gamma$ subunit in skeletal and smooth muscle but not in the heart $(12,13)$. Thus, subunit composition of the $\mathrm{Ca}^{2+}$ channel may determine some of the tissue-specific differences between $\mathrm{Ca}^{2+}$ channels.

\section{REFERENCES AND NOTES}

1. W. A. Catterall, Science 242, 50 (1988); P. Campbell, A. T. Leung, A. H. Sharp, Trends Neurosci. 11, 425 (1988).

2. H. Glossmann and J. Striessnig, Rev. Physiol. Biochem. Pharmacol. 114, 1 (1990); F. Hofmann, V. Flockerzi, W. Nastainszyk, P. Ruth, T. Schneider Curr. Top. Cell. Regul. 31, 223 (1990).

3. T. Tanabe et al., Nature 328, 313 (1987).

4. H. R. Guy and F. Conti, Trends Neurosci. 13, 201 (1990).

5. I. Lotan, P. Goelet, A. Gigi, N. Dascal, Science 243, 666 (1989).

6. A. Mikami et al., Nature 340, 230 (1989).

7. M. Biel et al., FEBS Lett. 269, 409 (1990).

8. M. Mori et al., Nature 350, 398 (1991).

9. K. S. De Jongh, C. Warner, W. A. Catterall, J. Biol. Chem. 265, 14738 (1990)

10. S. B. Ellis et al., Science 241, 1661 (1988).

11. P. Ruth et al., ibid. 245, 1115 (1989).

12. S. D. Jay et al., ibid. 248, 490 (1990).

13. E. Bosse et al., FEBS Lett. 267, 153 (1990).

14. M. Biel, V. Flockerzi, H. Hoffmann, unpublished observations.

15. F. C. Chang and M. M. Hosey, J. Biol. Chem. 263, 18929 (1988); M. E. Morton and S. C. Froehner, Neuron 2, 1499 (1989).

16. The cardiac $\alpha_{1}$ CDNA was cloned (M. Biel et al., Eur. J. Biochem., in press) by using the nucleotide sequence (6), the sequence was deposited in GenBank (X15539), and the recombinant plasmid pCaH carrying the protein coding sequence was constructed. The 3.3-kb Eco $\mathrm{RI}$ fragment from pCaCAl (6) containing the protein coding region of the $S M \alpha_{2} / \delta$ subunit was ligated with the Eco $R$ fragment from pSP65 [containing the 0.26-kb BgI II-Bam HI fragment carrying a poly(dA) poly(dT) tract from PSPCAl (6) at the Bam HI site], yielding PCA2. The recombinant plasmids $\mathrm{PCaBl}$ and pCaGl carrying the protein coding sequences of the SM $\beta$ (11) and $\gamma(13)$ subunit cDNA, respectively, were as in (8). mRNA (cRNA) of the cardiac $\alpha_{1}$ and skeletal muscle $\alpha_{2} / \delta, \beta$, and $\gamma$ subunits were synthesized in vitro with Asp718-cleaved PCaH, Sal I-cleaved pCaA2, Sal I-cleaved pCaB1, and Bam HI-cleaved pCaGl, respectively, as templates. Transcription was primed with the cap dinucleotide $\mathrm{m}^{7} \mathbf{G}\left(5^{\prime}\right) \operatorname{ppp}\left(5^{\prime}\right) \mathrm{G}(1 \mathrm{mM})$. In each experiment, 20 to 30 defolliculated oocytes were injected with 
cRNAs at 1:1:1:1 stoichiometry. After 3 or 4 days of incubation at $22^{\circ} \mathrm{C}(5)$, the oocytes were injected with 200 pmol of EGTA ( $\mathrm{K}^{+}$salt, $\mathrm{pH}$ 7) 1 day before testing the currents. $I_{\mathrm{B}}$ was measured at $22^{\circ} \mathrm{C}$ in $40 \mathrm{mM} \mathrm{Ba}^{2+}, 2 \mathrm{mM} \mathrm{K}^{+}, 60 \mathrm{mM} \mathrm{Na}^{+}$, and $5 \mathrm{mM}$ Hepes (pH 7.4 to 7.5); the anion was either $\mathrm{Cl}^{-}$or methanesulfonate. A low $\mathrm{Ba}^{2+}$ solution containing $2 \mathrm{mM} \mathrm{BaCl}_{2}, 96 \mathrm{mM} \mathrm{NaCl}, 2 \mathrm{mM} \mathrm{KCl}$, $5 \mathrm{mM}$ Hepes ( $\mathrm{pH} 7.5$ ) was used in some cases. The two-electrode voltage clamp, data acquisition, and subtraction procedures were as in (5). The precision of the rise time measurement was within $\pm 3 \mathrm{~ms}$ [ $\mathrm{N}$. Dascal and I. Lotan, Neuron 6, 165 (1991)]. The precision of current measurement was usually within $\pm 3 \mathrm{nA}$. The holding potential was $-80 \mathrm{mV}$. The $\mathrm{Ba}^{2+}$-dependent decrease in $I_{\mathrm{Ba}}$ in cells with large currents upon frequent repetitive depolarizations was avoided by using interpulse intervals that allowed a full recovery of $I_{\mathrm{Ba}}(5$ to $40 \mathrm{~s}$, depending on current amplitude).

17. N. Dascal, T. P. Snutch, H. Lubbert, N. Davidson, H. A. Lester, Science 231, 1147 (1986); J. A. Umbach and C. B. Gundersen, Proc. Natl. Acad. Sci. U.S.A. 84, 5464 (1987); P. Lory, F. A. Rassendren, S. Richard, F. Tiaho, J. Nargeot, J. Physiol. (London) 429, 95 (1990).

18. N. Dascal, I. Lotan, A. Gigi, E. Karni, manuscript in preparation.

19. R. G. Audet, J. Goodchild, J. D. Richter, Dev. Biol. 121, 58 (1987)

20. P. L. Donaldson and K. G. Beam, J. Gen. Physiol. 82, 449 (1983); J. A. Sanchez and E. Stefani, $J$. Physiol. (London) 337, 1 (1983); K. B. Walsh, T. B. Begenesih, R. S. Kass, J. Gen. Physiol. 93, 841 (1989).

21. The multiexponential character of $I_{\mathrm{Ba}}$ decay prevented a more rigorous analysis.

22. R. S. Kass and M. C. Sanguinetti, J. Gen. Physiol. 84, 705 (1984); K. S. Lee, E. Marban, R. W. Tsien, J. Physiol. (London) 364, 395 (1985); D. L. Campbell, W. R. Giles, J. R. Hume, E. F. Shibata, ibid. 403, 287 (1988).

23. In this solution, $\mathrm{Cl}^{-}$leaves the cell at all potentials, producing an inward current, which may introduce another artifact when $I_{\mathrm{Ba}}$ is large-an apparent slowing of the decay.

24. A. L. Hodgkin and A. F. Huxley, J. Physiol. (London) 117, 500 (1952). Only cells with $I_{\mathrm{Ba}}$ smaller than $-1500 \mathrm{nA}$ were tested. The inactivation curves were fitted to the equation $I_{\mathrm{B}} / I_{\max }=$ $1 /\left\{1+\exp \left[\left(V_{\text {prepulse }}-V_{1 / 2}\right) / K_{\mathrm{i}}\right]\right\}$, where $I_{\max }$ was the current obtained by the step from -100 to 20 $\mathrm{mV}$. For details on fitting procedure, see (31).

25. Steady-state inactivation was studied in the presence of Bay K in most cells of the $\alpha_{1}$ group and in some cells of the $\alpha_{1}+\gamma$ group to assure reliable measurement of currents. Bay $\mathrm{K}$ causes a slight (about 5 $\mathrm{mV}$ ) shift of the inactivation curve to negative potentials (29).

26. B. Hille, Ionic Channels of Excitable Membranes (Sinauer, Sunderland, MA, 1984); R. S. Kass and D. S. Krafte, J. Gen. Physiol. 89, 629 (1987).

27. T. Tanabe, K. G. Beam, B. A. Adams, T. Niidome, S. Numa, Nature 346, 567 (1990); E. Perez-Reyes et al., ibid. 340, 233 (1989); B. A. A. Adams, T. Tanabe, A. Mikami, S. Numa, K. G. Beam, ibid. 346, 569 (1990).

28. W. Stuhmer et al., Nature 339, 597 (1989); D. S. Krafte et al., J. Gen. Physiol. 96, 689 (1990); T. Hoshi, W. N. Zagotta, R. W. Aldrich, Science 250, 533 (1990)

29. A. M. Brown, D. L. Kunze, A. Yatani, J. Physiol. (London) 379, 495 (1986); S. Hering, T. Kleppisch, E. N. Timin, R. Bodewei, Pfluegers Arch. 414, 690 (1989)

30. C. Cognard, G. Romey, J.-P. Galizzi, M. Fosset, M. Lazdunski, Proc. Natl. Acad. Sci. U.S.A. 83, 1518 (1986); P. I. Aaronson, T. B. Bolton, R. J. Lang, I. MacKenzie, J. Physiol. (London) 405, 57 (1988).

31. We thank T. Tanabe and $S$. Numa for providing pSPCAl; D. Gordon, R. Korenstein, and S. Cohen for critical reading of the manuscript; Bay $\mathrm{K}$ was a gift from Bayer AG. Supported in part by grants from the Schlezak Fund to N.D. and I.L., Deutsche Forschungsgemeinschaft, Thissen and Fond der Chemischen Industrie to V.F. and F.H.

18 April 1991; accepted 31 July 1991

\title{
Resistance to ddI and Sensitivity to AZT Induced by a Mutation in HIV-1 Reverse Transcriptase
}

\author{
M. H. St. Clair, ${ }^{*}$ J. L. Martin, G. Tudor-Williams, M. C. Bach, \\ C. L. Vavro, D. M. King, P. Kellam, S. D. Kemp, B. A. Larder
}

Serial human immunodeficiency virus type-l (HIV-1) isolates were obtained from five individuals with acquired immunodeficiency syndrome (AIDS) who changed therapy to $2^{\prime}, 3^{\prime}$-dideoxyinosine (ddI) after at least 12 months of treatment with $3^{\prime}$-azido-3' deoxythymidine (zidovudine, AZT). The in vitro sensitivity to ddI decreased during the 12 months following ddI initiation, whereas AZT sensitivity increased. Analysis of the reverse transcriptase coding region revealed a mutation associated with reduced sensitivity to ddI. When this mutation was present in the same genome as a mutation known to confer AZT resistance, the isolates showed increased sensitivity to AZT. Analysis of HIV-1 variants confirmed that the ddI resistance mutation alone conferred ddI and $2^{\prime}, 3^{\prime}$-dideoxycytidine resistance, and suppressed the effect of the AZT resistance mutation. The use of combination therapy for HIV-1 disease may prevent drug-resistant isolates from emerging.

$\mathrm{E}$ XPERIENCE IN TREATING HIV-1-INfected individuals has raised concerns regarding therapy with antiviral agents. Several studies have drawn attention to the emergence of resistant HIV strains in individuals on long-term therapy with AZT alone $(1,2)$. The clinical implications of reduced susceptibility to AZT are not yet fully understood; the appearance of AZTresistant variants is not associated with a sudden clinical deterioration (1). Some individuals who have become intolerant to AZT or appear to be deteriorating clinically have changed therapy to other potentially effective drugs, including ddI (3), after discontinuing AZT. To discover if HIV isolates from such individuals develop resistance to ddI and if ddI therapy has any influence on AZT sensitivity we studied sequential isolates from five individuals who had received AZT for at least $\mathbf{1 2}$ months and were switched to ddI after they appeared to deteriorate clinically (4).

HIV was recovered from peripheral blood mononuclear cells (PBMCs) by cocultivation with donor $\mathrm{HIV}^{-}$PBMCs (5), and drug sensitivity was assessed with a PBMCbased assay (6). All isolates recovered at the time therapy was switched had reduced sensitivity to AZT. AZT therapy was discontinued and ddI started (with informed consent). Within 6 to 12 months of discontinuing AZT therapy, the isolates were

M. H. St. Clair, J. L. Martin, C. L. Vavro, D. M. King, Division of Virology, Burroughs Wellcome Co., Research Triangle Park, NC 27709.

G. Tudor-Williams, Division of Virology, Burroughs Wellcome Co., Research Triangle Park, NC 27709, and Duke University Medical Center, Durham, NC 27710. M. C. Bach, Maine Medical Center, Portland, ME 04102.

P. Kellam, S. D. Kemp, B. A. Larder, Division of Molecular Sciences, Wellcome Research Laboratories, Beckenham, Kent BR3 3BS, United Kingdom.

*To whom correspondence should be addressed. substantially more sensitive to AZT. During the same time period, a 6- to 26-fold decrease in ddI sensitivity was observed. A representative sensitivity profile for isolates from one individual is illustrated in Fig. 1. After 12 months of ddI therapy, the AZT $\mathrm{IC}_{50}(50 \%$ inhibitory concentration) had dropped from a high of greater than 10 $\mu \mathrm{M}$ to $0.73 \mu \mathrm{M} \mathrm{AZT}$, whereas the ddI $\mathrm{IC}_{50}$ 's for the same isolates increased from $0.3 \mu \mathrm{M}$ to $9 \mu \mathrm{M}$.

Studies have demonstrated that multiple common mutations in the HIV-l reverse transcriptase (RT) coding region confer resistance to AZT (7). Variants with reduced AZT sensitivity were found to contain one or more amino acid changes at codons 67 , 70,215 , or 219 . To identify mutations in the RT coding region associated with the observed resistance to ddI, we determined the complete nucleotide sequence of the

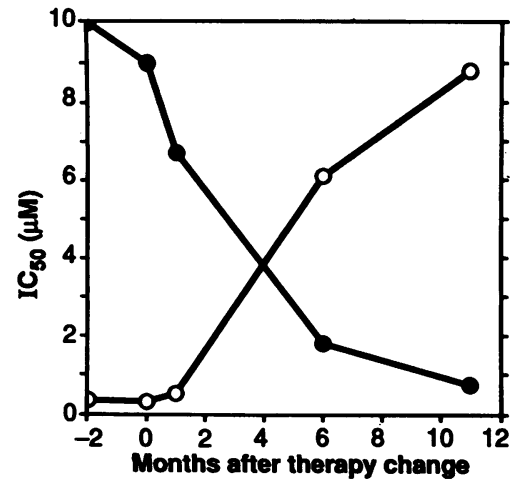

Fig. 1. In vitro sensitivities ( $\mathrm{IC}_{50}$ 's) to $\mathrm{ddI}(\mathrm{O})$ and AZT (O) of sequential HIV isolates from an individual with AIDS. This graph is illustrative of changes seen in five individuals (4). At time 0 AZT therapy was discontinued, and ddI therapy ( $4 \mathrm{mg}$ per kilogram of body mass every 12 hours) was initiated. Blood samples were obtained as shown before, at the time of, and at various times after the change in antiviral therapy. Virus was isolated and analyzed for sensitivity to AZT and ddI as described $(5,6)$. 